\title{
CHANGES IN QUALITY OF LIFE AMONG INDIAN BREAST CANCER PATIENTS DURING ADJUVANT TREATMENT: A SINGLE CENTRE EXPERIENCE
}

\author{
Abhishek Basu1, Abhijit Basu²
}

${ }^{1}$ Assistant Professor, Department of Radiotherapy, R. G. Kar Medical College, Kolkata.

2Senior Consultant Oncologist, Department of Radiation Oncology, Narayana Superspeciality Hospital, Howrah.

\begin{abstract}
AIMS AND OBJECTIVES

Although many studies on Quality of Life (QoL) have been conducted on female breast cancer patients worldwide, there have been very few studies in India. Our aim was to evaluate baseline QoL in Indian women with breast cancer and ascertain the changes in QoL during various phases of adjuvant treatment.
\end{abstract}

\section{MATERIALS AND METHODS}

In a prospective observational single centre study, QoL was assessed in 116 consecutive operated female breast cancer patients using the EORTC QLQ-C30 questionnaire at baseline after the 1st, $3^{\text {rd }}$ and $6^{\text {th }}$ cycles of adjuvant chemotherapy and twice during adjuvant radiotherapy.

\section{RESULTS}

Younger women and those from higher socio-economic families had lower function scale scores (Especially emotional and social function). Adjuvant chemotherapy caused substantial decrease in function scores and increase in symptom scale scores, especially nausea and vomiting, loss of appetite, fatigue and hair loss ( $p=N S$ ). Older women and those from lower socioeconomic strata tolerated chemotherapy better. Radiotherapy did not worsen QoL, and scores improved across the board in women during radiation.

\section{CONCLUSION}

Indian breast cancer patients have similar QoL issues with respect to women elsewhere. Younger women have generally poorer QoL both before and during therapy. Socioeconomic status is inversely related to QoL scores, irrespective of age. Radiotherapy is much better tolerated than chemotherapy.

\section{KEYWORDS}

Quality of Life, EORTC QLQ-C30, Breast Cancer, Chemotherapy, Radiotherapy.

HOW TO CITE THIS ARTICLE: Basu A, Basu A. Changes in quality of life among Indian breast cancer patients during adjuvant treatment: A single centre experience. J. Evolution Med. Dent. Sci. 2016;5(82):6101-6107, DOI: 10.14260/jemds/2016/1379

\section{BACKGROUND}

Cancer of the female breast is one of the most common malignancies among patients attending our hospital. The standard treatment of operable breast cancer remains judicious surgery followed by adjuvant systemic and local therapy using an appropriate combination of chemotherapy, radiotherapy and hormone therapy in hormone responsive patients. ${ }^{1}$ Quality of Life (QoL) is an important parameter in assessment of each patient's sense of physical, emotional and psychosocial wellbeing. ${ }^{2}$ It is now an accepted tool in reporting of any standard clinical trial. A number of factors influence the Quality of Life like age and socioeconomic condition. ${ }^{3}$ Quality of Life also changes significantly over time and with treatment and acts as a surrogate marker of the patient's global health status. ${ }^{3}$

\section{AIMS \& OBJECTIVES}

There have been some studies on Quality of Life in cancer

Financial or Other, Competing Interest: None.

Submission 06-09-2016, Peer Review 01-10-2016,

Acceptance 06-10-2016, Published 11-10-2016.

Corresponding Author:

Dr. Abhishek Basu,

Assistant Professor

Department of Radiotherapy,

R. G. Kar Medical College,

1, Khudiram Bose Sarani, Kolkata-700004.

E-mail: drabhishekbasu@yahoo.com

DOI: $10.14260 /$ jemds/2016/1379

\section{(c) (i) $(9$}

patients and the effect of treatment on overall functioning and wellbeing, but such studies have been very few in the Indian context. Our aim was to ascertain the Quality of Life in breast cancer patients undergoing treatment at our centre and analyse the changes in this parameter during various phases of treatment. We also endeavoured to assess effects of various factors like age, education and income on the changes in QoL scores during treatment.

\section{MATERIALS AND METHODS}

Period and Type of Study

From January 2009 to May 2010, a Prospective Observational Study was conducted by the authors at the Department of Radiotherapy, Medical College, Kolkata.

\section{Inclusion and Exclusion Criteria}

Subjects in our study were histopathologically proven female breast cancer patients (T1-3 N0-2 M0 according to AJCC TNM staging of Breast Cancer) attending our Outpatients Department. All patients were 18 years or older, had an ECOG Performance Status 0-2, normal baseline haematologic, renal and hepatic profiles and cardiac function at enrolment. None of the patients had clinical or radiological evidence of metastasis and all had undergone modified radical mastectomy without reconstruction prior to presentation with negative margins of resection. None of the patients had previous history of malignancy or exposure to cytotoxic chemotherapy or radiation. None were pregnant. There was no major comorbid physical or psychiatric illness in any of 
the patients and none of them were participating in any other clinical trial.

All the patients were literate and capable of understanding the questions in the questionnaires (In English or their respective vernaculars-Bengali or Hindi). The study was approved by the Institutional Ethical Committee. Informed consent was taken from all patients prior to enrolment.

\section{Study Design}

All patients were assigned to get adjuvant systemic chemotherapy (CT) with FAC regime consisting of Injections 5 -Fluorouracil $500 \mathrm{mg} / \mathrm{m}^{2}$, Doxorubicin $50 \mathrm{mg} / \mathrm{m}^{2}$ and Cyclophosphamide $500 \mathrm{mg} / \mathrm{m}^{2}$ IV with standard premedications on day 1 every 21 days for 6 cycles. Patients who were candidates for adjuvant radiation $(\mathrm{T} 3, \mathrm{~N}+)$ received External Beam Radiotherapy (EBRT) using Theratron $780 \mathrm{C}$ Telecobalt machine. Patients who were administered EBRT were given 50 Gy (@ 2Gy/fraction, 5 days a week) by medial and lateral tangential portals and supraclavicular fields (With CT based simulation), if indicated. The Quality of Life (QoL) was assessed by the 30-point EORTC QLQ-C30 version 3 and the Breast Cancer specific BR 23 version 1 questionnaires or their Bengali or Hindi validated translations approved by the EORTC Quality of Life Working Group.2,4 All patients were asked to self-answer the questionnaires in adequate privacy without any time pressure. They were informed that they need not answer questions that they feel inappropriate or unanswerable. The patients were assessed at presentation, after the $1^{\text {st }}, 3^{\text {rd }}$ and $6^{\text {th }}$ cycles of chemotherapy and in patients who underwent radiation, once 2 weeks after starting radiation and after completing EBRT. All patients received chemotherapy in the indoor wards and EBRT on outpatient basis.

\section{Analysis of Data \\ The QLQ-C30 questionnaire consists of items arranged as three scales-Functional (physical, role, social, emotional, cognitive); Symptomatic (dyspnoea, pain, fatigue, insomnia, appetite, nausea vomiting, constipation, diarrhoea and financial difficulties) and Global Health Status/QoL.2,4 The Breast Cancer specific BR 23 is a supplement to the QLQ-C30 which has similar scales-Functional (body image, future perspective) and Symptomatic (systemic therapy side effects, breast symptoms, arm symptoms and hair loss).2,4 The Raw Score (RS) was calculated as the mean of all the data for each individual scales. 5 The range was calculated as the difference between the maximum possible and the minimum possible value of RS. ${ }^{5}$ (Most items are scored 1 to 4 , giving range $=3$. The exceptions are the items contributing to the global health status/QoL, which are 7-point questions with range=6.) Using the RS and Range, the values were linearly transformed to a scale of 0-100 to give score $S$ by the given formulas: ${ }^{5}$}

Functional Scales: $\mathrm{S}=\{1-(\mathrm{RS}-1) /$ range $\} \times 100$.

Symptom Scales/Items: $S=\{($ RS -1$) /$ range $\} \times 100$.

Global Health Status/QoL: $S=\{1-($ RS-1)/range $\} \times 100$.

Higher values in the function and QoL scales indicate better level of functioning/higher QoL whereas higher values in the symptom scales indicate increased symptoms/difficulties. Missing data were accounted for according to the method prescribed in the EORTC Manuals. ${ }^{5}$ Scores for individual patients were analysed and mean of scores of all patients for each parameter were calculated.

The reliability and validity of the English and translated versions (Bengali and Hindi) of the questionnaires were tested by Cronbach's alpha test (0.63-0.94) and item-scale correlation (0.59-0.91).

\section{STATISTICAL ANALYSIS}

Statistical analysis was done using Repeated Measures Oneway Analysis Of Variance (ANOVA) with Dunnett's post-test was performed using the GraphPad Prism version 5.00 (for Windows, GraphPad Software, San Diego, California, USA). P values $<0.05$ were considered significant. All $p$ values reported are two tailed.

\section{RESULTS}

Between January 2009 and May 2010, we enrolled 120 consecutive patients who met the inclusion criteria. The baseline patient profile is listed in Table 1. One hundred and sixteen patients ultimately underwent the trial. Of the 4 patients who missed, 1 had a histology different from Infiltrating Duct Carcinoma and 3 did not complete therapy due to various reasons. The menopausal status was defined as per NCCN Guidelines v 1.2009.6 Patients who studied till class $\mathrm{V}$ were designated as Up to Mid School, those who studied up to class X were designated as Up to High School \& those who studied beyond were designated as Higher Education. Of the total 116 patients, a majority of $57 \%$ were ER-. Although 23 were HER2/neu overexpressed, adjuvant anti-HER2 therapy was not used to financial constraints. Early Breast Cancer (EBC) was defined as AJCC7 T1-T2N0M0 and Locally Advanced Breast Cancer was defined as AJCC T13N1M0 and T3N0M0 (Operable LABC). Most patients (39\%) were in AJCC stage group IIB. All patients completed per protocol chemotherapy. The median treatment duration for CT was 19.5 weeks (With 13 patients not being able to complete the 6 cycles on time) and EBRT was 6.7 weeks (7 patients not being able to complete on time). High risk features included presence of either high grade, lymphovascular invasion and/or positive proliferation markers. Ninety three percent of the patients could be given full doses of drugs during CT. Seventy seven patients required per protocol post-mastectomy EBRT.

Translated and validated local language questionnaires were used for most $(84 \%)$ of the patients with the Bengali version for $68 \%$ and Hindi version for $16 \%$ patients. Analysis of QoL at baseline (Table 2) revealed better functional scores for women who were older, less educated and economically backward. Working women had better scores. Younger women and those with higher education or family income had especially poor scores in emotional function. The major symptoms at presentation were fatigue and lack of appetite. Younger women having children $<10$ yrs. had poorer emotional scores and QoL.

Quality of Life was assessed after 1 ${ }^{\text {st }}$ (CT 1), $3^{\text {rd }}$ (CT 3) and $6^{\text {th }}$ (CT 6) cycles of chemotherapy and twice during the course of EBRT (After 2 weeks of starting radiation and after completion).

Mean Physical (PF2) and Role Function (RF2) Scores were (Table 3) 62.3 and 61.1 at baseline, 58.4 and 56.3 after CT 1, 60.5 and 58.0 after CT 6, 62.1 and 64.6 during EBRT 
(two weeks after starting; EBRT 2 weeks) and 67.9 and 66.4 after completion of radiotherapy (EBRT COMPL). There was a clear trend of decrease in scores from baseline after CT 1 (Table 3) with gradual improvement subsequently (Table 4; Figure 1). Younger women and those who were better educated or from higher income families had poorer scores. Working women had consistently higher scores than their non-working counterparts. Cognitive function remained more or less same throughout therapy.

There was substantial decrease in Emotional and Social Function (EF, SF) Scores during chemotherapy (43.4 vs. 51.2 at baseline for EF and 46.3 vs. 55.9 for SF after CT1; p=NS) and appreciable improvement during EBRT (Table 4; Figure 1). These scores were especially lowered in younger, nonworking females with LABC and those who had young children. However, these subgroups also showed maximum improvement in scores during radiotherapy, and most subsets had better scores than their baseline, by the time they completed EBRT. Body Image scores (BRBI) remained fairly low throughout and were lower in younger women of higher socioeconomic class.

The predominant symptoms at baseline survey were fatigue, insomnia and lack of appetite. Some patients also complained of symptoms at the chest flap or arm region. After CT 1, there was substantial increase in nausea-vomiting (39.6 after CT 1 vs. 22.3 at baseline; $p=0.562$ ) and loss of appetite ( 44.3 vs. 31.7 at baseline; $p=0.711$ ), especially in younger, more well off women (Figure 2). Working and elderly women had lower symptoms throughout. Hair loss was a major concern among all women, irrespective of age or socioeconomic stratification. High scores of 56.9 and 59.1 after CT 1 and CT 3 gradually decreased after CT completion and during EBRT. As expected, younger women were much more concerned than other subgroups (64.8 vs. 56.9 after CT1; $p=0.648$ ). Older women complained more of constipation or diarrhoea. Interestingly, women with EBC had more symptoms like nausea, loss of appetite and insomnia than patients with LABC.

Most of the symptoms scores remained fairly uniform during the course of chemotherapy and improved during EBRT. However, there was a slight increase in fatigue and loss of appetite and a slight decrease in nausea throughout the course of chemotherapy. Breast and arm symptoms were more at presentation due to patients coming after surgery. Of note, breast symptoms decreased steadily through therapy whereas arm symptoms remained pretty high. Older, working and better educated women reported more financial difficulties but surprisingly, women from both lower and higher income families had fairly similar scores in this regard (23.2 vs. 25.8).
The patient cohort was subsequently followed up. Sixteen patients were lost to followup. The 3-year disease-free survival was $76 \%$ with twenty four patients failing-nine locoregionally and fifteen distally. Significant (Grade 3) late toxicities were found in 18 patients with lymphoedema, arm mobility restriction and subcutaneous fibrosis being most common. Quality of life was not assessed after treatment as per the trial design.

\begin{tabular}{|c|c|}
\hline Characteristics & \% Distribution \\
\hline \multicolumn{2}{|c|}{ Age } \\
\hline $20-40$ & 36 \\
\hline $40-60$ & 45 \\
\hline$>60$ & 19 \\
\hline \multicolumn{2}{|c|}{ Menopausal Status } \\
\hline Premenopausal & 61 \\
\hline Postmenopausal & 39 \\
\hline \multicolumn{2}{|c|}{ Type of Cancer } \\
\hline EBC & 42 \\
\hline LABC & 58 \\
\hline ER Positive & 43 \\
\hline ER Negative & 57 \\
\hline \multicolumn{2}{|c|}{ Stage Group } \\
\hline I A & 0 \\
\hline I B & 0 \\
\hline II A & 27 \\
\hline II B & 39 \\
\hline III A & 34 \\
\hline \multicolumn{2}{|c|}{ Parity } \\
\hline $0-2$ & 29 \\
\hline $2-4$ & 46 \\
\hline$>4$ & 24 \\
\hline \multicolumn{2}{|c|}{ Educational Qualifications } \\
\hline Up to Mid School & 53 \\
\hline Up to High School & 35 \\
\hline Higher Education & 12 \\
\hline \multicolumn{2}{|c|}{ Family Income per Month } \\
\hline$<$ Rs. 2000 & 29 \\
\hline Rs. 2000-10000 & 52 \\
\hline > Rs. 10000 & 18 \\
\hline \multicolumn{2}{|c|}{ Working } \\
\hline Yes & 27 \\
\hline No & 73 \\
\hline \multicolumn{2}{|c|}{ ECOG Performance Status } \\
\hline 0 & 28 \\
\hline 1 & 57 \\
\hline 2 & 15 \\
\hline
\end{tabular}

\begin{tabular}{|c|c|c|c|c|c|c|c|c|c|c|c|c|c|}
\hline \multirow[t]{2}{*}{ Scores } & \multicolumn{2}{|c|}{ Stage } & \multicolumn{3}{|c|}{ Age (In Yrs.) } & \multicolumn{3}{|c|}{ Education } & \multicolumn{3}{|c|}{$\begin{array}{l}\text { Family Income } \\
\text { (Rs. / Month) }\end{array}$} & \multicolumn{2}{|c|}{ Working } \\
\hline & EBC & LABC & $20-40$ & $40-60$ & $>60$ & $\begin{array}{l}\text { Up to Mid } \\
\text { School }\end{array}$ & $\begin{array}{c}\text { Up to } \\
\text { High } \\
\text { School }\end{array}$ & $\begin{array}{c}\text { Higher } \\
\text { Education }\end{array}$ & $<5000$ & $\begin{array}{l}5000- \\
10000\end{array}$ & $>10000$ & Yes & No \\
\hline PF2 & 73.2 & 59.4 & 68.3 & 59.7 & 48.1 & 71.4 & 62.9 & 61.4 & 69.3 & 62.7 & 55.9 & 70.9 & 60.4 \\
\hline RF2 & 67.3 & 56.7 & 67.2 & 56.9 & 50.4 & 65.9 & 59.4 & 54.3 & 61.5 & 60.3 & 58.1 & 63.6 & 59.1 \\
\hline $\mathrm{CF}$ & 87.5 & 79.8 & 88.6 & 82.3 & 72.2 & 78.3 & 80.5 & 89.2 & 80.8 & 82.4 & 86.7 & 84.3 & 76.8 \\
\hline$\overline{E F}$ & 62.1 & 54.9 & 43.9 & 52.6 & 63.1 & 63.7 & 56.1 & 46.0 & 63.0 & 59.7 & 56.8 & 63.7 & 54.9 \\
\hline SF & 66.3 & 53.0 & 47.0 & 58.5 & 69.4 & 57.3 & 59.5 & 63.8 & 55.9 & 61.5 & 64.4 & 65.0 & 59.3 \\
\hline BRBI & 52.5 & 45.2 & 40.8 & 45.3 & 51.9 & 44.2 & 42.6 & 36.1 & 46.6 & 45.1 & 41.2 & 48.8 & 41.2 \\
\hline
\end{tabular}




\begin{tabular}{|c|c|c|c|c|c|c|c|c|c|c|c|c|c|}
\hline BRFU & 62.8 & 47.7 & 35.5 & 43.9 & 61.7 & 56.6 & 51.9 & 41.4 & 46.5 & 49.3 & 53.7 & 50.3 & 61.1 \\
\hline DY & 9.3 & 16.9 & 8.7 & 14.4 & 17.0 & 9.1 & 11.3 & 17.4 & 11.3 & 10.4 & 16.0 & 10.6 & 16.6 \\
\hline$\overline{P A}$ & 18.4 & 28.6 & 16.8 & 22.1 & 27.3 & 18.2 & 20.5 & 29.6 & 16.5 & 22.8 & 34.4 & 18.3 & 26.9 \\
\hline FA & 24.1 & 32.7 & 22.3 & 26.9 & 30.5 & 22.7 & 27.8 & 36.9 & 21.7 & 26.5 & 37.0 & 22.3 & 34.8 \\
\hline SL & 19.4 & 25.8 & 24.9 & 21.6 & 19.5 & 20.5 & 23.2 & 31.6 & 19.9 & 23.4 & 31.6 & 20.7 & 24.1 \\
\hline$\overline{\mathrm{AP}}$ & 34.2 & 46.9 & 31.7 & 37.0 & 33.1 & 35.7 & 37.3 & 42.6 & 36.9 & 37.2 & 45.4 & 32.9 & 38.1 \\
\hline NV & 11.4 & 15.3 & 20.9 & 14.2 & 10.7 & 12.6 & 13.5 & 20.9 & 13.4 & 14.1 & 23.7 & 11.9 & 14.7 \\
\hline $\mathrm{CO}$ & 13.5 & 21.0 & 9.6 & 14.3 & 26.9 & 14.8 & 14.2 & 21.6 & 14.7 & 16.9 & 22.3 & 15.5 & 19.0 \\
\hline DI & 9.8 & 12.1 & 6.8 & 9.4 & 14.3 & 9.9 & 10.4 & 11.1 & 10.6 & 11.2 & 10.8 & 11.4 & 11.2 \\
\hline BRBS & 17.5 & 15.6 & 13.9 & 11.0 & 8.7 & 14.1 & 15.6 & 17.9 & 15.8 & 13.0 & 11.2 & 15.5 & 14.6 \\
\hline BRAS & 18.9 & 16.3 & 20.3 & 16.6 & 18.1 & 16.9 & 12.0 & 22.5 & 12.7 & 16.4 & 14.1 & 15.7 & 17.2 \\
\hline QL & 56.4 & 48.9 & 45.7 & 51.3 & 57.8 & 53.3 & 54.5 & 46.8 & 49.2 & 50.5 & 52.6 & 59.9 & 45.1 \\
\hline FI & 37.9 & 41.6 & 46.8 & 42.2 & 39.0 & 35.7 & 42.4 & 43.1 & 57.9 & 48.6 & 38.3 & 46.7 & 39.1 \\
\hline
\end{tabular}

Abbreviations: Function Scales: QLQ C30: PF2-Physical Functioning (Revised); RF2-Role Functioning (revised); CF- Cognitive Functioning; EF-Emotional Functioning; SF-Social Functioning; BR 23: BRBI-Body image; BRFU-Future Perspective; Symptom Scales: QLQ C30: DY-Dyspnoea; PA-Pain; FA-Fatigue; SL-Insomnia; AP-Appetite; NV-Nausea and Vomiting; CO-Constipation; DIDiarrhoea; FI-Financial Difficulties; BR 23: BRBS-Breast Symptoms; BRAS-Arm Symptoms; Global Health Status/Quality of Life Scale:QL.

\begin{tabular}{|c|c|c|c|c|c|c|c|c|c|c|c|c|c|}
\hline \multirow[t]{2}{*}{ Scores } & \multicolumn{2}{|c|}{ Stage } & \multicolumn{3}{|c|}{ Age (In Yrs.) } & \multicolumn{3}{|c|}{ Education } & \multicolumn{3}{|c|}{$\begin{array}{l}\text { Family Income } \\
\text { (Rs./Month) }\end{array}$} & \multicolumn{2}{|c|}{ Working } \\
\hline & EBC & LABC & $20-40$ & $40-60$ & $>60$ & $\begin{array}{c}\text { Up to } \\
\text { Mid } \\
\text { School }\end{array}$ & $\begin{array}{c}\text { Up to } \\
\text { High School }\end{array}$ & $\begin{array}{c}\text { Higher } \\
\text { Education }\end{array}$ & $<5000$ & $5000-10000$ & $>10000$ & YES & NO \\
\hline PF2 & 64.9 & 52.6 & 61.6 & 53.0 & 42.5 & 65.3 & 59.1 & 54.7 & 61.4 & 57.3 & 50.5 & 56.9 & 61.3 \\
\hline RF2 & 60.1 & 52.3 & 57.4 & 52.7 & 49.6 & 60.0 & 53.5 & 48.5 & 60.6 & 56.4 & 49.8 & 57.6 & 50.1 \\
\hline $\mathrm{CF}$ & 85.4 & 80.1 & 86.9 & 80.3 & 73.4 & 78.7 & 79.9 & 86.5 & 79.4 & 81.0 & 85.6 & 82.9 & 75.8 \\
\hline EF & 55.6 & 49.4 & 38.6 & 47.9 & 57.3 & 56.5 & 50.1 & 40.2 & 53.8 & 49.4 & 43.9 & 55.7 & 49.6 \\
\hline SF & 57.2 & 50.4 & 41.2 & 52.3 & 60.7 & 49.9 & 52.7 & 56.6 & 49.3 & 54.6 & 58.1 & 53.3 & 50.7 \\
\hline BRBI & 52.5 & 45.2 & 40.8 & 45.3 & 51.9 & 44.2 & 42.6 & 36.1 & 46.6 & 45.1 & 41.2 & 48.8 & 41.2 \\
\hline BRFU & 62.8 & 47.7 & 35.5 & 43.9 & 61.7 & 56.6 & 51.9 & 41.4 & 46.5 & 49.3 & 53.7 & 50.3 & 61.1 \\
\hline DY & 9.3 & 16.9 & 8.7 & 14.4 & 17.0 & 9.1 & 11.3 & 17.4 & 11.3 & 10.4 & 16.0 & 10.6 & 16.6 \\
\hline PA & 18.4 & 28.6 & 16.8 & 22.1 & 27.3 & 18.2 & 20.5 & 29.6 & 16.5 & 22.8 & 34.4 & 18.3 & 26.9 \\
\hline FA & 24.1 & 32.7 & 22.3 & 26.9 & 30.5 & 22.7 & 27.8 & 36.9 & 21.7 & 26.5 & 37.0 & 22.3 & 34.8 \\
\hline SL & 19.4 & 25.8 & 24.9 & 21.6 & 19.5 & 20.5 & 23.2 & 31.6 & 19.9 & 23.4 & 31.6 & 20.7 & 24.1 \\
\hline $\mathrm{AP}$ & 34.2 & 46.9 & 31.7 & 37.0 & 33.1 & 35.7 & 37.3 & 42.6 & 36.9 & 37.2 & 45.4 & 32.9 & 38.1 \\
\hline NV & 11.4 & 15.3 & 20.9 & 14.2 & 10.7 & 12.6 & 13.5 & 20.9 & 13.4 & 14.1 & 23.7 & 11.9 & 14.7 \\
\hline $\mathrm{CO}$ & 13.5 & 21.0 & 9.6 & 14.3 & 26.9 & 14.8 & 14.2 & 21.6 & 14.7 & 16.9 & 22.3 & 15.5 & 19.0 \\
\hline DI & 9.8 & 12.1 & 6.8 & 9.4 & 14.3 & 9.9 & 10.4 & 11.1 & 10.6 & 11.2 & 10.8 & 11.4 & 11.2 \\
\hline BRBS & 27.5 & 35.6 & 33.9 & 31.0 & 22.7 & 24.1 & 27.6 & 37.9 & 25.8 & 29.0 & 31.2 & 25.5 & 34.6 \\
\hline BRAS & 30.9 & 37.3 & 40.3 & 36.6 & 28.1 & 26.9 & 32.0 & 42.5 & 22.7 & 26.9 & 34.1 & 26.7 & 35.2 \\
\hline \multicolumn{14}{|l|}{ BRST } \\
\hline \multicolumn{14}{|l|}{ BRHL } \\
\hline QL & 56.4 & 48.9 & 45.7 & 51.3 & 57.8 & 53.3 & 54.5 & 46.8 & 49.2 & 50.5 & 52.6 & 59.9 & 45.1 \\
\hline FI & 37.9 & 41.6 & 46.8 & 42.2 & 39.0 & 35.7 & 42.4 & 43.1 & 57.9 & 48.6 & 38.3 & 46.7 & 39.1 \\
\hline
\end{tabular}

Abbreviations: Function Scales: QLQ-C30: PF2-Physical Functioning (Revised); RF2-Role Functioning (Revised); CF- Cognitive Functioning; EF-Emotional Functioning; SF-Social Functioning; BR 23 :BRBI-Body image; BRFU-Future Perspective; Symptom Scales: QLQ-C30: DY-Dyspnoea; PA-Pain; FA-Fatigue; SL-Insomnia; AP-appetite; NV-Nausea and Vomiting; CO-Constipation; DIDiarrhoea; FI-Financial Difficulties; BR 23: BRBS-Breast Symptoms; BRAS-Arm Symptoms; BRST-Side Effects of Systemic Therapy; BRHL-Hair Loss; Global Health Status/Quality of Life Scale: QL.

\begin{tabular}{|c|c|c|c|c|c|}
\hline \multirow{2}{*}{$\begin{array}{c}\text { QoL } \\
\text { Scales }\end{array}$} & \multicolumn{5}{|c|}{ Mean Scores } \\
\cline { 2 - 6 } & $\begin{array}{c}\text { Base } \\
\text { Line }\end{array}$ & $\begin{array}{c}\text { After } \\
\text { CT 1 }\end{array}$ & $\begin{array}{c}\text { After } \\
\text { CT 6 }\end{array}$ & $\begin{array}{c}\text { After EBRT } \\
\text { 2 WKS. }\end{array}$ & $\begin{array}{c}\text { After EBRT } \\
\text { COMPLETION }\end{array}$ \\
\hline PF2 & 62.3 & 58.4 & 60.5 & 62.1 & 67.9 \\
\hline RF2 & 61.1 & 56.3 & 58.0 & 64.6 & 66.4 \\
\hline
\end{tabular}




\begin{tabular}{|c|c|c|c|c|c|}
\hline $\mathrm{CF}$ & 82.5 & 80.6 & 81.4 & 81.8 & 80.3 \\
\hline $\mathrm{EF}$ & 51.2 & 43.4 & 46.5 & 54.8 & 59.0 \\
\hline SF & 55.9 & 46.3 & 52.1 & 53.7 & 56.8 \\
\hline BRBI & 50.6 & 41.3 & 44.2 & 45.0 & 41.8 \\
\hline BRFU & 52.8 & 47.3 & 48.2 & 50.5 & 54.9 \\
\hline DY & 10.3 & 14.6 & 18.7 & 23.2 & 22.6 \\
\hline PA & 26.8 & 22.4 & 25.7 & 21.1 & 23.0 \\
\hline FA & 32.9 & 43.6 & 49.2 & 40.9 & 36.6 \\
\hline SL & 39.6 & 41.7 & 40.3 & 34.5 & 32.1 \\
\hline $\mathrm{AP}$ & 31.7 & 44.3 & 48.2 & 32.5 & 27.7 \\
\hline $\mathrm{NV}$ & 22.3 & 39.6 & 35.9 & 28.4 & 21.0 \\
\hline $\mathrm{CO}$ & 13.8 & 19.7 & 24.0 & 16.2 & 17.4 \\
\hline DI & 9.5 & 13.3 & 15.9 & 12.6 & 13.1 \\
\hline BRBS & 24.3 & 28.9 & 22.0 & 19.4 & 25.5 \\
\hline BRAS & 26.7 & 29.5 & 22.4 & 18.1 & 26.9 \\
\hline BRST & - & 46.8 & 53.9 & 43.3 & 35.6 \\
\hline BRHL & - & 56.9 & 52.7 & 43.5 & 31.1 \\
\hline QL & 54.9 & 46.8 & 50.2 & 56.7 & 59.5 \\
\hline FI & 24.5 & 33.9 & 37.8 & 29.6 & 26.2 \\
\hline \multicolumn{6}{|c|}{$\begin{array}{l}\text { Table 4: Changes in QoL Scores during Treatment (Using EORTC QLQ-C30 v3.0 and BR } 23 \text { v1.0) } \\
\text { (n=116 for chemotherapy, } n=77 \text { for EBRT) }\end{array}$} \\
\hline
\end{tabular}
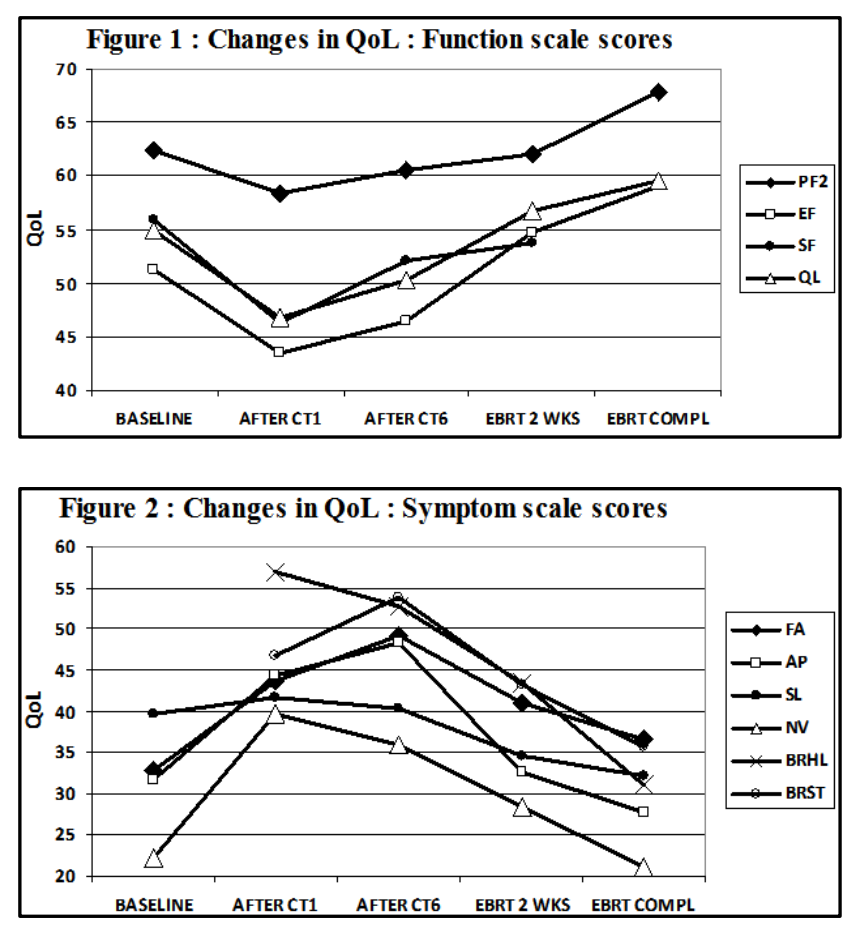

\section{DISCUSSION}

There are a number of scoring methods for QoL assessment including the EORTC QLQ-C30, the Subjective Significance Questionnaire (SSQ) and the Functional Assessment for Cancer Therapy-General (FACT-G). Numerous studies have validated the EORTC QLQ-C30 questionnaire.2,8,9 Of importance, a study from Tata Memorial Hospital, Mumbai has validated the EORTC questionnaires in the Indian population and also recommended use of the regional language versions. ${ }^{8}$

In our study, we tried to minimise variations in treatment modalities to enable more uniform comparison among the patients. Studies have shown that breast conserving surgery (BCS) was consistently associated with better QoL scores, especially with regards to body image, in comparison to modified radical mastectomy (MRM).10,11,12 Because it was not possible to ensure breast conservation in all patients, and choosing a population, where some patients had BCS and others had MRM, would place the latter group at a distinct disadvantage vis-a-vis QoL scores, we deliberately chose only those patients who had undergone MRM. Similarly, we kept the regime, interval and number of cycles of chemotherapy and the dose and treatment portals of radiotherapy same. Hypofractionated EBRT, although gaining popularity now, was not standard at the time of this trial and was hence not used. Adjuvant endocrine therapy (Tamoxifen $20 \mathrm{mg}$ OD for premenopausal women or Anastrozole $1 \mathrm{mg}$ /Letrozole 2.5 mg OD for postmenopausal women) was added in ER positive patients after EBRT completion. Anti-HER-2/neu therapy was not used. This allowed us to properly interpret effect of age, socioeconomic status, education etc. on changes in QoL during treatment.

A problem that we faced was regarding responses to questions regarding sexual wellbeing. None of the patients were willing to answer these questions. Consequently, we did not include responses to this section of the BR-23 questionnaire in our analysis. This problem is probably unique to Indian society and has not been commonly reported in Western literature.

Age is an important factor in interpreting Quality of Life.13,14,15,16 Younger women are especially at high risk for having lower QOL.14,15,16 Younger breast cancer survivors are at risk for impaired QOL up to several years after diagnosis.15,16 Breast cancer patients who had been diagnosed at an older age showed worse QOL outcomes in the physical domain, while those who had received diagnoses at a younger age showed worse QOL outcomes in the social and emotional and perception of body image domains. ${ }^{14,15,17}$ Our study corroborated these facts in the Indian context. Moreover, we found higher education, family income and working status to have a clear inverse relationship with most QoL function scale scores. Another finding of importance was lower scores both prior to and during therapy in younger women who had small children. Expectedly, body image 
problems were more in younger women of higher socioeconomic strata.

During treatment, there was a global deterioration of functional scores during chemotherapy and gross improvement (In some cases, beyond baseline scores) during radiotherapy. This is similar to findings of other studies in breast cancer patients which show decrease in physical, role and social function during chemotherapy $8,17,18,19$ and good, stable QoL scoring during radiotherapy indicating that it was well tolerated. ${ }^{20}$ Studies show that fatigue, sleep disturbances and pain were moderately intense during treatments and decreased significantly over time.17,18,19 Our patients had similar complaints with loss of appetite ranking as one of the other major symptoms.

Treatment outcomes were different with respect to age, as in other studies, with younger women reporting higher symptoms and poorer QoL than their older counterparts. ${ }^{13-19}$ We also found poorer QoL scores in more educated working women of higher income families. Nausea and vomiting was a major symptom during chemotherapy peaking after the first cycle, but decreasing gradually thereafter. The trends showed a steep rise in symptom scores combined with a sharp decline in emotional and social function and QoL after the $1{ }^{\text {st }}$ cycle of chemotherapy (compared to baseline) probably owing to initial anxiety and adjustment to a new therapeutic intervention. The scores did not alter hugely with subsequent cycles and some scores actually improved. Although the exact reason for this is not clear, it may be due to patients getting used to chemotherapy and its effects better with repeated cycles. Hair loss was a major problem and accounted for worse socio-emotional scores in all women but more so in the young.

Drawbacks of our study were the small number of patients and inability to ascertain changes over a long period of time, especially considering long term late effects due to sequel of treatment or disease relapse. We intend to conduct a larger study that assesses QoL parameters in Breast Cancer patients over time, starting before treatment and continuing through longterm followup, in a bigger patient population, based on this initial study.

\section{CONCLUSIONS}

Quality of Life in breast cancer patients and its alteration during treatment is of paramount importance, but is unfortunately, often underestimated. Breast cancer patients in India face similar problems and respond in similar fashion to their counterparts elsewhere in the world. The effect of age, education, family income and working status on various QoL scores is clearly defined in our patients. Adjuvant chemotherapy causes substantial worsening whereas Radiotherapy maintains and improves Quality of Life. As Oncologists, we need to appreciate these findings and incorporate them in our day-to-day practice. Larger studies are required to better understand QoL issues in breast cancer patients in India.

\section{REFERENCES}

1. Burstein HJ, Harris JR, Morrow M. Malignant Tumors of the Breast. In: DeVita VT, Hellman SA, Rosenberg SA. eds. Cancer principles \& practice of oncology. $8^{\text {th }}$ edn. Philadelphia, USA: Lippincott Williams \& Wilkins Vol. 2. 2008:1620-41.
2. Aaronson NK, Ahmedzai S, Bergman B, et al. The European organisation for research and treatment of cancer QLQ-C30: a quality-of-life instrument for use in international clinical trials in oncology. J Nat Can Inst 1993;85(5):365-76.

3. Härtl K, Jaani W, Kastner R, et al. Impact of medical and demographic factors on long-term quality of life and body image of breast cancer patients. Ann Oncol 2003;14(7):1064-71.

4. The EORTC QLQ C 30 and BR 23 questionnaires accessible from http://www.eortc.be/home/qol/ Last accessed: November $20^{\text {th }}, 2015$.

5. Fayers PM, Aaronson NK, Bjordal K, et al. On behalf of the EORTC quality of life group. The EORTC QLQ-C30 scoring manual. $3^{\text {rd }}$ edn. Brussels: European Organisation for Research and Treatment of Cancer 2001.

6. National Comprehensive Cancer Network (NCCN) Practice guidelines in oncology: Breast. Pdf version 2. 2009. accessible from http://www.nccn.org Last accessed December 13 $3^{\text {th }}, 2015$.

7. Greene FL, Page DL, Fleming ID, et al. AJCC cancer staging manual $6^{\text {th }}$ edn. New York, NY: Spinger-Velrag 2002.

8. Parmar V, Badwe RA, Hawaldar R, et al. Validation of EORTC quality-of-life questionnaire in Indian women with operable breast cancer. Nat Med J Ind 2005;18(4):172-7.

9. McLachlan SA, Devins GM, Goodwin PJ, et al. Validation of the European organization for research and treatment of cancer quality of life questionnaire (QLQ-C30) as a measure of psychosocial function in breast cancer patients. Eur J Cancer 1998;34(4):510-7.

10. Arndt V, Stegmaier C, Ziegler H, et al. Quality of life over 5 years in women with breast cancer after breastconserving therapy versus mastectomy: a populationbased study. J Cancer Res Clin Oncol 2008;134(12): 1311-8.

11. Curran D, van Dongen JP, Aaronson NK, et al. Quality of life of early-stage breast cancer patients treated with radical mastectomy or breast-conserving procedures: results of EORTC trial 10801. The European organization for research and treatment of cancer (EORTC), breast cancer co-operative group (BCCG). Eur J Cancer 1998;34(3):307-14.

12. Schou L, Ekeberg Q, Sandvik L, et al. Multiple predictors of health-related quality of life in early stage breast cancer. Data from a year follow-up study compared with the general population. Qual Life Res 2005;14(8):1813-23.

13. Hopwood P, Haviland J, Mills J, et al. The impact of age and clinical factors on quality of life in early breast cancer: an analysis of 2208 women recruited to the UK START Trial (Standardisation of Breast Radiotherapy Trial). Breast 2007;16(3):241-51.

14. Watters JM, Yau JC, O'Rourke K, et al. Functional status is well maintained in older women during adjuvant chemotherapy for breast cancer. Ann Oncol 2003;14(12):1744-50.

15. Cimprich B, Ronis DL, Martinez-Ramos G, et al. Age at diagnosis and quality of life in breast cancer survivors. Cancer Pract 2002;10(2):85-93. 
16. Avis NE, Crawford S, Manuel J, et al. Quality of life among younger women with breast cancer. J Clin Oncol 2005;23(15):3322-30.

17. Osoba D, Rodrigues G, Myles J, et al. Interpreting the significance of changes in health-related quality-of-life scores. J Clin Oncol 1998;16(1):139-44.

18. Byar KL, Berger AM, Bakken SL, et al. Impact of adjuvant breast cancer chemotherapy on fatigue, other symptoms, and quality of life. Oncol Nurse Forum 2006;33(1):E1826.
19. Browall M, Ahlberg K, Karlsson P, et al. Health-related quality of life during adjuvant treatment for breast cancer among postmenopausal women. Eur J Oncol Nurs 2008;12(3):180-9.

20. Arraras JL, Manterola A, Dominguez MA, et al. Impact of radiotherapy on the quality of life of elderly patients with localized breast cancer. A prospective study. Clin Trans Oncol 2008;10(8):498-504. 